\title{
Mulao Chinese
}

National Cancer Institute

\section{Source}

National Cancer Institute. Mulao Chinese. NCI Thesaurus. Code C158187.

A Chinese person from the Mulao (including the Qago) ethnic group. 